\title{
Transgressing Power and Identity Re-Formation in Martin Amis's Money
}

\author{
Marwan Kadhim Mohammed ${ }^{1,}$, * , Wan Roselezam Wan Yahya ${ }^{2, b}$ \\ ${ }^{1,2}$ Faculty of Modern Languages and Communication, University Putra Malaysia, Malaysia \\ aalkubaisy71@gmail.com, ${ }^{b}$ roselezam@gmail.com
}

Keywords: Transgression, Foucault, Power, Identity, Amis, Money.

\begin{abstract}
Martin Amis's manipulation of the patriarchal concept of power is a notable indication of his transgressive attitudes that raise remarkable questions about the human identity. Transgressing power investigates the violation of the normal and familiar trends of literature in order to circulate a new discourse by which a new identity is reframed. Hence, the study of power in Martin Amis's novels, as an important technique of identity re-definition, is not taken into consideration in the light of Michel Foucault's theory of power. The objective of this study is to examine the role applied by transgression as a technique of subverting the common discourse of power in the field of identity re-formation. The study investigates the concept of power manipulated in Amis's Money to define the identity of the 'New Man'. Accordingly, the Foucauldian theory of power is taken as a framework of this study. The study reveals a conclusion in which the transgressive aspects of power are effectively utilized by Amis to re-define the identity of his protagonist in the novel. Although John Self has finally lost his name and fortune, which are necessary demands to define one's self in the patriarchal society, he finds his own new identity away from the materialistic norms of the common discourse.
\end{abstract}

\section{Introduction}

The affective and purposeful nature of transgression as a creative technique of change offers a wide scope of interpretation for a lot of behavioral aspects of human beings. Transgression related to such a sense of discovery, adventure and change, usually involves the human activity to express itself. In this regard, transgression is instrumental in playing a vital role in human activities of existence. As a result, transgression, as a one of these activities, applies a significant part in framing and shaping the human identity and subjectivity. Therefore, transgression provides a prominent field of study in the scope of identity research and study. However, this field of study does not fully take into concern the important part of transgression in shaping and framing the human identity. Although Martin Amis's contemporary attempts of transgressing social and literary norms have not missed this scope and field of study but they are not fully taken into accounts. Amis's transgressive novels have not been widely echoed in the field of identity construction and constitution.

Nevertheless, nowadays studies of identity offer prominent attempts to permeate the importance of transgression in framing and shaping the human identity and subjectivity. Transgression as an instrumental approach of constituting identity is taking into consideration. To demonstrate, Thomas Waugh's study under the title The Romance of Transgression in Canada explores, to certain extent, the transgressive approaches of making the social and human identity [18]. Waugh examines the cultural and social representation of transgression in framing the human identity. A new aspect of transgression has been conducted in this study to meet the social and cultural representation of identity formation and constitution.

Besides, transgression is a crucial nowadays theme in the study field of identity and subjectivity because transgression has in touch with the human behavior and existence. In this connection, Paula Ruth Gilbert's study entitled The Violated Female Body as Nation: Cultural, Familial, and Spiritual Identity in Nora Okja Keller's Comfort Woman addresses the theme of transgression in Nora Okja Keller's novel Comfort Woman [8]. The recalling of the past transgressive events is interrogated to explore the role of these events in framing the Korean identity in the novel. Gilberta concludes that the protagonist's national identity is reconstructed in accordance to the transgression applied by the protagonist himself. 
Further, the smart study entitled Performing Jesus: A Queer Counternarrative of Embodied Transgression is conducted by Tricia Sheffield who tries to draw attentions to the importance of transgression in forming and shaping the individual identity [14]. Sheffield explains that transgression can play a vital role in re-reading and re-thinking the classic stories of 'heretical' or 'monstrous' protagonists. Sheffield concludes that these processes of rereading and rethinking can portray the importance of transgression in shaping the identity of those narrative characters.

The relation between transgression and identity is, also, the main theme of article under the title Transgression: Body and Space conducted by Rachael Sara and David Littlefield [13]. The article examines the role played by transgression in the field of subjectivity and identity constitution. The interrelation of architecture and society is discussed to investigate the theme of identity construction. The study concludes that the idea of transgression is indispensable in defining thinking and understanding of shaping our identities.

Transgression as a technique in the re-formation of identity was also discussed in $R e$ Gendering Discourse Adrienne Rich's Snapshots of A Daughter-in-Law by Hassan \& Talif [10]. The article is conducted in the light of Kristeva's concept of the semiotic and symbolic. According to Kristeva, the semiotic transgresses the symbolic mode of signification in order to create new discourses of identity reconstruction.

Meanwhile, the present study portrays a new perspective for examining transgression in Martin Amis's novel Money by following a new approach of tracing the re-establishment of identity throughout the manipulation of the concept power in terms of Foucauldian theory. The concept of power is transgressed to circulate such a new system in which power is re-shaping and re-framing the individual identity. The patriarchal concept of power is subverted to create a new discourse in which identity is re-established. The new conceptualization of identity asserts that "the postmodern self is no longer a coherent entity that has the power to impose order upon its environment" [2]. The patriarchal conceptualization of power is subverted to circulate a new discourse in which power positively plays a vital role in constituting identity and framing subjectivity. In this connection, Hans Bertens portrays his viewpoints of power in shaping the identity of postmodern man to meet the Foucauldian one as it "is no longer a coherent entity that has the power to impose order upon its environment. It has become decentered" [2]. The patriarchal conceptualization of power is subverted to circulate a new being of identity formation.

To illustrate, the present paper aims at investigating the transgression of power in Martin Amis's Money as it turns into a technique by which identity is reconstructed and reshaped. This transgression takes the form of power reflected through certain behavioral qualities that the characters obtained and/or offered to present their own identities. The transgressive conceptualization of power is developed through subverting and violating the traditional concept of power asserted by human presence. By this sense of development a new discourse of meanings of power is circulated to help producing a new identity.

Amis, most precisely, brings up profound issues about power and identity in his novel Money to assert his attestation of transgression. The concept of power as a remarkable notion in his novel is subverted to remark its huge attestations on the individual identity and subjectivity. With this subversion, the idea of power is transgressed to mirror the transgression of the human self. Identity is depicted as a changeable construction which is effectively transformed; it is not a fixed and steady construct. Subsequently, the individual self becomes a good site of power conflicting and contradicting. In this connection, Slethaug remarks that the mission of nowadays writers "assumes that the human being is a locus of contradictions in a reality of conflicting discourses and discursive practices". Further, in this thought of inconsistency and contradiction the modern identity is affirmed and confirmed in "the split sign, the split self, and the split text" [15].

Through his portrayal of ideas of contradictions, Amis reveals his conceptualization of identity in the light of transgressive power of masculinity. The patriarchal concept of masculinity and power is repudiated to circulate a new discourse of power in which identity is reframed. In such a manner, Amis confirms Foucault's recognitions that transgression of power is unavoidable for reconstituting and reframing the individual identity of the modern man. 
Also, Amis's novel Money investigates and appreciates a new discourse in which the identity is reconstituted by means of subverting and transgressing power. In the same way of appreciation, Amis agrees with Foucault's conceptualization of identity formation and subjectivity definition. Amis goes with Foucault's ideas of transgression depicted as "an action which involves the limit, that narrow zone of a line where it displays the flash of its passage" [6]. Subsequently, the limit and the way of going beyond it assume a remarkable part in reframing and reshaping the individual identity since limit "has its entire space in the line it crosses" [6].

\section{Foucauldian Power}

The concept of power is a crucial idea in Foucault's theory of transgression. His theory investigates the relation between power and knowledge and how power is used to portray the constitution of identity and the definition of subjectivity. It is plainly separated with the Marxist and all other previous understandings and conceptualizations of power. In his theory of transgression, Foucault developed an approach that emphasized the part which power plays in the circulation of a new discourse in society. Foucault argues that power is basically not something that institutions and establishments can possess and use abusively against people. Foucault goes beyond the traditional and patriarchal meaning of the concept of power as a means of oppression used by the powerful against the powerless, planning to look at how power works in normal communications between individuals and establishments. In this context, power is more like something that can be circulated in a certain and special way that helps portraying and framing the individual identity. This way refers to power as a more like strategy than a possession. Furthermore, Foucault looks at power as a process and a means of resistance which is a productive and profitable component, in light of the fact that it has beneficial outcomes. One of these important outcomes is the individual's self- construction. Besides, power is omnipresent and can be found in any kind of relation between the individuals of the society.

Leaning on this concept of power as a prominent idea of the theory of transgression, scholar had used Foucauldian concept to give their views and opinions. Foucault's idea of power and resistance was addressed in a study under the title Power, Subtraction and Social Transformation: Canetti and Foucault on the notion of Resistance conducted by Andrea Mubi Brighenti [3]. In this study, the concept of power as a means of resistance is analyzed to be an essential practice of negation and transgression. The study transgresses the traditional concept of resistance by suggesting a different conceptualization of creation and change in terms of Canetti's and Foucault's theories. The comparison between the concepts of resistance in the two adopted theories uncovers a new hypothetical venue for the idea of resistance as a demonstration that summons the shared trait of people. The study provides a good presentation of Foucauldian concept of power in framing the human personality and identity.

Foucault's political philosophy of power and resistance implied another idea of militancy which is addressed in Mads Peter Karlsen and Kaspar Villadsen's study entitled Foucault, Maoism, Genealogy: The Influence of Political Militancy in Michel Foucault's Thought [11]. The article discusses Foucault's conceptualization of power as a concept of transgression to deal with history concentrated on another dialog accomplice, in particular, the Marxist convention and, all the more definitely, French Maoism. The purpose of the study aims at explaining how standards, grown in Maoist political activism, were not just acknowledged in Foucault's exercises inside the GIP [the Maoist-inspired activist group], but also in his theory of genealogy and lectures of power adopted by Foucault. The study discusses the concept of power as a standard grown in Maoist political activism.

Another study about the Foucauldian conceptualization of power as a transgressive concept is entitled as A Different Life?: Barthes, Foucault and Everyday Life conducted by Patrick Ffrench [5]. The study is a clear investigation of the idea of difference in modern terms of philosophical works. A different thinking and rethinking of life in works of Roland Barthes and Michel Foucault are traced to discuss the transgressive portrayal of power. Barthes' critical analysis of ideology and myth and Foucault's assessment of power relations are taken as the most important accounts of the 
French theorists for their strategies of the new different life. The study makes use of Barthes' and Foucault's concepts of power to assert and conclude the features of the new life and the new identity.

Jeffrey Dirk Wilson, also, discusses the concept of power in the Foucauldian theory of transgression in a paper entitled Foucault as Inverted Neo-Platonist in "A Preface to Transgression" [19]. Wilson analyzes the Foucauldian theory of transgression by following its main notions and concepts of power. The study argues that reading Foucault's very important essay A Preface to Transgression is inevitable in understanding the theme of Neo-Platonism. Such argument is asserted by making a comparison between a passage from Foucault's essay with another one from characteristic enneads of Plotinus. Wilson justifies such comparison with his claim that Foucault had already read the works of Plotinus. Such reading, Wilson emphasized, had left its effects on Foucault's style of writing and thought of transgression.

\section{Discussion}

The individuals' bad conditions and situations of the $20^{\text {th }}$ century find their ways in Martin Amis's novels to reflect the form of suppression and persecution of the age. Novels such us Time's Arrow, London Fields, and Money, to great extent, outline the negative impact of the controlling and maneuvering industries on the modern individuals. The serious results of this impact are portrayed by Amis to reveal his sever satire of these maneuvering industries and the age as a whole. To do this, Amis resorts to a new type of creation in which a transgressive vision of reality is manipulated to portray the identity of the human being and age alike. The transgressive portrayal of characters like, Odilo, Keith, and John Self, exemplifies Amis's viewpoint of the spiritual decay embodied throughout the sexual and materialistic triumphs of modern age. The protagonists are altogether ruled by their fixations, sex, drives and a complete submission to their desires and interest most conspicuously money.

As Amis's novel Money is concerned, the protagonist John Self is depicted as a truly naïve character who is widely affected by the casualties and attitudes of the age most remarkably the capitalism and the power of money. Money: A Suicide Note is a clear representation of the cultural and liberal life of the modern community in the eighties of the twentieth century. Throughout the portrayal of the life of its protagonist, John Self, the novel depicts the modern life of London and New York.

Moreover, Money tells the story of John Self who falls a victim to the powers of his unquenchable sexual desires, passion, and money which are exposed as the spoiler of human value and life. Self is meant to be portrayed with a mixed inception and origin, half American and half a British. The mixed origin represents the diversity of cultures under the rule of both Thatcher and Reagan, the political leaders in both Britain and America. Thus, the novel is set in 1981 to paint the political and cultural caricatured portraits of London and New York under the policies of those rulers. These two cities are taken as a satiric target for the novelist to represent the interchangeable centers of greed in the novel since those rulers were remarkably known with their financial policies. The novel, for instance, implies the Royal Wedding of Prince Charles and Diana, to overthrow indications of the new political atmosphere of the eighties which portrayed as the age of money. For this period of time Amis believes that "the money age we're living through now is a short-term, futureless kind of prosperity [. . .], a 'live now, pay later' thing. Money is a more democratic medium than blood, but money as a cultural banner--you can feel the whole society deteriorating around you because of that" [17].

Besides, the mixed cultural idea of origin supports and justifies Self's worship of money. Self's expressions of feelings are always doomed with expressions of money and its relatedness. These expressions are meant to reflect the cultural life of Self's origin and position. To illustrate this, Self is situated between his country of origin [England] and his essential country of business [United States] and neither of these countries is fixed as his home. The novel is related in both London and New York and Self is positioned at home in both and neither. This state of instability in any of these cities metaphorically refers to a sense of spiritual homelessness. The spiritual homelessness is intentionally given to Self to find a free space for his power of passion and fondness to grow up and come into being. 
Most accurately, in New York Self makes a surrogate "home" in his hotel room and sets up an offbeat, familial, bond with Felix, the bellhop, based upon unbelievable tips. In London Self's quest for a private space is undermined by the impact of his girlfriend, Selina Street, whose requests to be permitted to live in his level test his feeling of sacred space and rootedness. Certainly, even his certified familial connections offer little in the method of strong history and origin. The man he has dependably thought to be his dad is uncovered to be an impostor, who not only provides Self with a deliberately ordered bill for his childhood and upbringing, but additionally masterminds an agreement of beating to be implied on his 'son'. Therefore, Self is unable to position himself in the terms of any steady birthplaces and origins. Moreover, he is unable to defend himself in any terms of origins and develops instead a complete sense of alienation. Thus, he readily splits himself from origins and transgresses the past to portray instead a new identity and a new man.

The new obtained identity is completely defined in terms on the most powerful concept of the age, that is, money. Self's realization and definition of the new identity goes forward through his commitment to a money-greed that supports his capacity to judge and gain power. Therefore, money in the novel is empowered to be used as a compensation of Self's homelessness and past origin. Self remarks that "money is freedom. That's true. But freedom is money" [1]. The mutual relation between freedom and money gives a sense of power of freedom that money could provide. The freedom obtained by money circulates a powerful sensation that can come from that money. In another case, Self alludes that "making lots of money is a breeze" [1] by which one can find his new identity. In this situation, Self also concludes that "money is very versatile" which can give such a sense of power enough to adapt or be adapted to compensate one's origin and home by creating new powerful alternatives for him since this sense of power " is full of interesting things" [1].

Further, transgression in Money frames not only the cultural life of the modern age, but also, the new identity of its protagonist. Amis transgresses expectations at depicting the incapacitating creativity of his narrator who is not conscious of neither controlling powers practiced by both his dearest companions and relatives, nor of the way that his British creator utilizes him differently as a narrative model for his investigation of the bases of human discourse of transgression. This model of transgression is embodied by the common discourses of oppression and exploitation applied by power on the expense of the cultural aspects of the age. John Self, a gullible semi-unskilled and unreliable narrator, stays ignorant of most of the modern aspect of culture. For example he stays unaware of literature in spite of being consistently familiar, or, from his point of view, besieged with the information about famous literary canons, generally given to him by his American girlfriend Martina Twain. The ignorance leaves him at last unable to grasp the themes of individuals' transgression and the circumstances of his ruin.

Moreover, John Self is a representative of the modern era, who lives on the margins of culture involved with materialistic desires and concerns. The materiality of the modern age takes a large transgressive space of Self's thinking and mind. As a producer of absurd TV commercial ads, Self is raised on the explicit entertainments of sex, pornography, fast food and money. In such a life of transgressive and materialistic concerns, Self believes that money is his only god. It is demonstrated like a destructive god. This kind of transgressive demonstration is a real exemplification of the power of money that Amis means to indicate as a result of transgression. The money, earlier in the novel, is meant to be something powerful. This sense of power is the actual reason behind calling money a 'suicide note' in the subtitle of the novel. The destructive and transgressive nature of money will lead Self to ruin himself at the end of the novel. Consequently, Self is drove to the loss of his fortune and his name because of the destructive and transgressive nature of his god 'money'. Amis draws attention to the idea in which "money is always connected with excrement in myth" [16]. Self embodies Amis's words of connection to say that "money, now this has to be some good shit" [1]. This sense of connection implies the destructive and transgressive nature of money that Amis would like to give to his protagonist in Money.

Besides, Self, as a transgressive implication of Amis's thought and philosophy, supports such idea of suicide and destruction when he alludes to the powerful things which money can do. Money is professional enough to give others such a powerful sense of care and comfort. Self's relation to 
money, for example, is very passionate since the money, he believes, is the "only one Earthling who really cares about me". This sense of relation is portrayed as a matter of a powerful loyalty. In this sense, Self says "at least, this human being loyally follows me around the place, keeps tabs on me and rings me up the whole time". It is such a close relation and "no one else can does. Selina's never there. All the others - it's just money". Money is powerfully elevated to be "the only thing we have in common. Dollar bills, pound notes, they're suicide notes. Money is a suicide note" [1]. This powerful sense of care, comfort and loyalty with money is revealed to be fake and false because this money itself will drive Self to his ruin and destruction.

On the other hand, money is portrayed as a power of control that demonstrates the lives of human beings. Because of its powerful nature, money controls everything and cannot be controlled as Self remarks that "I have money but I can't control it...Money, I think, is uncontrollable" [1]. Self even generalizes this conception of control to include not only those who do not have it but even others who do have. Therefore, he uses the pronoun "us" when he talks about the control of money to enlarge the scope of that control. Self indicates that "even those of us who have it, we can't control it. Life gets poor-mouthed all the time, yet you seldom hear an unkind word about money" [1]. The powerful and dominant nature of money shows it as able to go in all times and directions without being questioned. Therefore, Self compares money with aging when he says that "the ageing and the money, the things that move past us uncontrollably while we just stay the same" [1]. Money is compared to aging to allude that money like aging moves forward without any retreat.

In addition, more transgressive touches of power are implied in the novel to portray the new identity of its protagonist. The unrestrained self of the modern man and his passion for money is fully represented throughout the character of John Self whose all his relations, actions, and activities are dominated and decided by money. Self shows a complete surrender and submission to the power of money. In this connection, money is empowered to impose its rules on the protagonist and other characters of the novel. Money has a full power to reframe and redefine the identity of individuals submitted to its discourse. In this regards, Foucault indicates that power has its way to circulate its discourse to redefine the identity of human being. Therefore, Self remarks that "money makes you innocent when it's been there all along."[1]. In this context, Amis reflects a Foucauldian concept of identity in which power is productive source of that identity. Thus, Amis frames his conceptualization of identity with that of power to meet Self's claim that money can reshape one's identity as innocent. Similarly, Amis's Money, through its discourse of power, portrays the sense of freedom through money power people look for. Self refers to this money power when he says that "Nothing liberates women like money does" [1]. In this connection, Amis renders his concept of freedom and liberation which is completely compatible with Foucault's orientations of the same concept that portrays the new identity of the modern man. Foucault calls for respecting individual freedom in that one is free to choose his life style.

In addition, Amis himself explains Self's transgressions of the social norms as a quest for a new discourse in which he could be defined with a new identity. For example, Amis justifies Self's utilization of alcohol as "more a painkiller than a quest for a good time" [9]. Self is not looking for a good time with his drinking rather; he looks for a new discourse by which he could define his identity. Similarly, Self's explicit transgression of sexual life is the result of having seen a lot of recordings, videos, and magazines that offer sex as a powerful product. In some senses, Amis's claim explains to certain extent the idea behind Self's resort to transgressive sex and pornography. Self's move forward in this direction is a kind of manipulation and resistance of his submission for the power of money. Self's transgression is a clear indication for his attempt to define his identity with a new sense of resistance to get rid of the dictated discourse of power imposed by money. In this connection, Foucault's slogan of resistance that "where there is power, there is resistance" [7] finds its way in Self's identity. For this reason, Self tries to resist the power of money to survive and to liberate himself from money mania. Accordingly, Self portrays his new identity of power by transgressing the dictated discourse of power imposed by money. To illustrate, Self's transgression of the dictated discourse of money power generates a new discourse of power to face the dictated one. Self is depicted as a lamentable, peculiar and transgressive character that shows up a lot of 
submission to the power of money. However, he is turned to be complex and cryptic concerning exposing his power to fight with other characters in the novel. In his struggle of money with Fielding Goodney's persecution Self shows at last a long distance of manipulation to survive and escape his fate and destination. In this regard, Self remarks:-

All that morning when death felt so near and life seemed such good stuff - I never called for help. My life has been a fight between shame and fear. In suicide shame wins. Shame is stronger than fear, though you still feel shame. You still fear fear, in my case, and suddenly you want to call the whole thing off. In the finished suicide, shame wins, but you wouldn't want anyone to see it winning. Suicide is so shameful. I would have hated anyone to see me at it. No, I wouldn't have been seen dead in the bathroom there, committing suicide like that [1].

Self has set the general features of his new identity in two main things. Firstly, he does not ask for help from others and secondly, he hates committing suicide. Although, the suicide is related earlier with money in the title of the novel as an indication of a close connection, Self expresses his hatred of suicide which implicitly refers to his rejection of submission to the power of money. These two features are remarkable definitions of Self's new identity. Further, Self's new identity is also emerged through comparing his former life full of money with his new life free of money. The comparison shows to certain extent a sense of powerful aspects of comfort and safety in his life because of his creation of a new identity that resists the powerful discourse of money. Self alludes that:-

I want my money again but I feel better now that I haven't got any. There are these little pluses. You, they can't do much to you when you haven't got any money. There's no money in it for them. So they can't be fucked. I've been rich and I've been poor. Poor is worse, but rich can be a clunker, too $[1]$.

In this context, Amis is fully compatible with Foucault's conceptualization of resistance in stating that "where there is power there is a resistance" [7]. Self sets a new transgressive and resistant identity for himself as a reaction for the power circulated by money.

The discourse of power circulated by money is present everywhere and every time in the novel. In this concern, Amis echoes Foucault's notes about power that is "found in every kind of relationship, as a condition of the possibility of any kind of relationship" [12]. Hence, Self's sexual portrayal with Selina, his faithless English sweetheart, usually reveals some talks about money. Self says that "while making love, we often talk about money. I like it. I like that dirty talk" [1]. On the other hand, Selina herself is promoting her sexual advance, and not condemning that kind of talks. Self is not the most elevated individual of his community. He is really fallen a victim of the eighties policies of consumerism, and TV business. The majority of his sexual encounters come officially by his submersion in the financial and porn business. To illustrate, Self is frank representative of his generation of the eighties for whom money needs to be taken as a supreme value of society. He believes that money empowers people to move forward in their lives and without which such a move cannot happen. In this regard, Self remarks that "the streets are full of movement but hardly anybody goes where they go through thought or choice, free of money motive. Only people with money do that" [1]. Only the moneymen can be empowered to go forward in life because they are "much more powerful stuff" [1].

Moreover, the discourse of money power cast its shadow on the social norms to circulate such a sense that money is the most recognized and remarkable quality that displays people. Money is the most notable touch that promotes people's importance and significance. Therefore, in his description of the people in the street, Self refers only to the people who have money and he mentions nothing about the other people who have no money as if they are unseen. He remarks that:- 
there are some pretty primitive creatures driving around with money in their Torpedoes and Boomerangs, or sitting down with money at the Mahatma or the Assisi, or just standing there with money, in the shops, in the pubs, in the streets" $[1]$.

The common idea to all those described people is money. Therefore, the word money is repeated three times in one sentence to emphasize such a notable quality. It is worth noting that the word money has been repeated in all the pages of the novel up to more than 510 times starting from the title page till the last one of the novel. Self goes in his description of people to indicate that "they are all shapes and colors, innocent beneficiaries of the global joke which money keeps cracking" [1]. The most important idea of all this description is that those people "don't do anything: it's their currencies that do things" [1]. The power of money is elevated to replace people and to do things instead of them. With this sense of power, money is indicated as a supreme power that Self has to take care of. For that reason Self shows his complete submission and weakness when he beseeches and asks money to tell him about things he has no idea about "I have no ideas on this one. Tell me, please. Money doesn't tell me" [1].

Money focuses on the problems of insecurity and the desperate attempts of modern man to obtain power and control to enrich his feeling of safety. This focus is meant to show the discourse of power circulated by money. During the modern era, money has been confirmed as one of the powers of control if it is not the strongest. The human passion of control affirms the greedy quest for power through money to become the most prominent features of the modern era. Relaying on this modern materialistic thought, Amis delineates his portrait of power of money via his characterization of Self as the protagonist of his novel Money. Self's state of mind, as a greedy, materialistic product of this modern age, becomes governed by his male fantasies and yearnings. Further, Amis underlines a close correlation between his figuration of Self and the literary Shakespearean image of Othello who is obsessed with his powerlessness, impotence and indignity and his seek to compensate for this by imposing control over women. Therefore, in his discussion of the film scenario with the other actors, Self reveals his viewpoint asserting that "the way I see it, Butch has never had an orgasm before she meets this wonderful guy, who shows her a world she's only dreamed of, a world of Othello jets and Caribbean mansions" [1]. Self's viewpoint shows that both his maleness and fundamental use of money can be used against woman's humiliation and maltreatment. James Diedrick, in some sense, goes further to claim that Self gets more resemblance to Roderigo than to Othello and he refers to Coleridge's assessment of Roderigo, stating that it may be applied to John Self. Therefore, Diedrick remarks that "the want of character and the power of the passions, like the wind loudest in empty houses, forms his character" [4].

Finally, it is worth mentioning that Self's loss of all of his money and name does not prevent him to begin a new life and a new love story with Georgina. He goes on his way to start a new life far away from all the materialistic life that he had accustomed before. The impartiality of that materialism forms an important motivation to Self to move on in his way away from the former life and to become a new man by drawing a new identity. It is true that he is "not proud" of his new life but in any case he is "delighted ..., and powerfully confident" at the end [1].

\section{Conclusion}

The theme of identity re-formation is a major concern in Amis's novel Money. Following the Foucauldian discourse of power, this paper concludes that transgressing the common discourse of power plays a definite part in the process of identity re-formation. John Self redefines his identity and realizes his subjectivity when he transgresses the common discourse of power. This type of transgression creates a new identity powerful enough to resist the discourse of power already circulated. Losing all of his fortune and name gives Self the chance to reconsider his identity away from the materialistic influences of his society. In view of Foucault's concept of transgressing power, Self is empowered through his transgression of the discourse of power circulated by money. Thus, he liberates himself from the submission to the power of money which in turn helps in his 
evolution to the idea of a 'New Man'. In this connection, Self reveals the death of the materialistic system of money as the only crucial key-player in re-forming identity. His withdrawal of this materialistic system asserts Amis's confirmation of the failure of materialism in defining one's identity. Self's going forward with a new identity in Money paves the way to the emergence of new discourse of identity re-formation away from the materialistic discourse of power.

\section{References}

[1] Amis, Martin. "Money: A Suicide Note. 1984."Harmonds worth: Penguin (1985).

[2] Bertens, Hans, The postmodern Weltanschauung and its relation to modernism: An introductory survey, A postmodern reader. (1993) 25-70.

[3] Brighenti, Andrea Mubi, Power, subtraction and social transformation: Canetti and Foucault on the notion of resistance, Distinktion: Scandinavian Journal of Social Theory (rDIS). 12:1 (2011) 57-78.

[4] Diedrick, James, Understanding Martin Amis. University of South Carolina Press, 1995.

[5] Ffrench, Patrick, A different life?: Barthes, Foucault and everyday life, Cultural studies. 18:2-3 (2004) 290-305.

[6] Foucault, Michel, A preface to transgression, Language, counter-memory, practice: Selected essays and interviews. (1977) 29-52.

[7] Foucault, Michel, The history of sexuality. Volume one: An introduction, 1980.

[8] Gilbert, Paula Ruth, The Violated Female Body as Nation: Cultural, Familial, and Spiritual Identity in Nora Okja Keller's Comfort Woman, Journal of Human Rights 11:4 (2012) 486-504.

[9] Haffenden, John, Salman Rushdie. Novelists in Interview, New York, 1985, 1-24.

[10] Hassan, Mohamad Fleih, and Rosli Talif, Re-gendering discourse in adrienne rich's snapshots of a daughter-in-law, Malaysian Journal of Languages and Linguistics. 3:1 (2014) 67-77.

[11] Karlsen, Mads Peter, and Kaspar Villadsen, Foucault, Maoism, Genealogy: The Influence of Political Militancy in Michel Foucault's Thought, New Political Science. 37:1 (2015) 91-117.

[12] M.G. Kelly, The political philosophy of Michel Foucault, Routledge, London, 2010.

[13] Sara, Rachel, and David Littlefield, Transgression: Body and Space, Architecture and Culture. $2: 3$ (2014) 295-304.

[14] Sheffield, Tricia, Performing Jesus: A queer counternarrative of embodied transgression, Theology \& Sexuality. 14:3 (2008) 233-258.

[15] Slethaug, Gordon, The Play of the Double in Postmodern American Fiction, SIU Press, 1993.

[16] Smith, Amanda, Martin Amis (PW Interviews), Publishers Weekly. 8 (1985).

[17] Stout, Mira, Down London's Mean Streets, New York Times Magazine. 4 (1990) 32-36.

[18] Waugh, Thomas, Romance of transgression in Canada: Queering sexualities, nations, cinemas, McGill-Queen's Press-MQUP, 2006.

[19] J.D. Wilson, Foucault as Inverted Neo-Platonist in "A Preface to Transgression", Metaphysical Society of America, 62 ${ }^{\text {nd }}$ Annual Meeting Emory University, 10-12 March 2011. 